\title{
Compressive Strength of Three Types of Heat-Cure Acrylic Resins: Acropars, Acrosun, and Meliodent
}

\author{
Ammar Neshati ${ }^{1}$, Negin Kouchak Dezfouli ${ }^{10}$, Mehdi Sadafi ${ }^{1}$, Shahab Omidi ${ }^{2}$ \\ ${ }^{1}$ Faculty of Dentistry, Department of Prosthodontics, AJA University of Medical Sciences, Tehran, Iran. \\ Islamic Azad University of Medical Science,Tehran, Iran. \\ ${ }^{2}$ Dentist, DDS, Faculty of Dentistry, Islamic Azad Tehran University of Medical Science, Tehran, Iran
}

\begin{tabular}{l} 
ARTICLE INFO \\
\hline Article History \\
Received:June 2021 \\
Accepted: August 2021 \\
ePublished: Oct 2021 \\
\hline Corresponding author \\
Negin Kouchak Dezfouli \\
,Dentist, DDS, Faculty of \\
Dentistry, Islamic Azad \\
Tehran University of \\
Medical Science, Tehran, \\
Iran \\
Email: - n.k.dezfuli@ \\
gmail.com
\end{tabular}

\begin{abstract}
Background and Aim: Compressive strength of acrylic resin base is an effective factor on durability of a prosthesis. The purpose of this in vitro study was to compare the compressive strength of three different types of heat-cure acrylic resins. Materials and Methods: In this in vitro experimental study, 60 acrylic samples were fabricated from Acropars, Acrosun, and Meliodent acrylic resins ( $n=20$ from each). The specimens were placed in a universal testing machine, and force was applied until their fracture. The load at fracture was recorded as the compressive strength. Data were analyzed using one-way ANOVA followed by the Tukey's test. Results: The mean compressive strength was $80.6 \pm 6.9,85.6 \pm 6.9$, and 71.9 $\pm 5.3 \mathrm{MPa}$ for Acropars, Acrosun, and Meliodent, respectively. The compressive strength of Acrosun was significantly higher than that of other groups $(\mathrm{P}=0.047)$. Conclusion: In general, the results showed that the highest and the lowest compressive strength values were related to Acrosun and Meliodent, respectively. These results indicated the optimal compressive strength of Iranian acrylic resins. Keywords: Acrylic Resins; Compressive Strength; Polymethyl Methacrylate
\end{abstract}

J Res Dent Maxillofac Sci 2021;6(4):14-17.

\section{Introduction}

Although dental implants are a more favorable option for replacement of the lost teeth, removable dentures are still considered as an alternative treatment for patients suffering from systemic diseases or severe jawbone atrophy. ${ }^{(1)}$ Various substances have been introduced as denturebase materials such as metal and heat-cure resins. Metal is not a desirable choice compared with other available materials since it cannot meet the esthetic requirements, and cannot bond to other denture structures. $^{(2)}$

Acrylic denture bases are more popular due to their physical and chemical properties which enable relining and have optimal handling and esthetic properties as well. ${ }^{(3)}$ Acrylic resin materials are low weight and cheap, and have acceptable biocompatibility,esthetics, and color match with the natural tissue. ${ }^{(4)}$
Some concerns exist regarding the fracture of acrylic resin under heavy occlusal forces or trauma. $^{(5)}$

Denture base acrylic resin is mainly composed of polymethyl methacrylate (PMMA). PMMA is the preferred material for removable denture base and implant-supported restorations. Pure PMMA is a clear thermoplastic material that provides the opportunity of color matching with the tissue by adding plasticizers and cadmium. Its polymerization can be activated chemically or by light irradiation, microwave energy, or hot water. Activation of heat-cure acrylic resins is done by releasing free radicals. (6) These materials are supplied in the form of powder and liquid. Many attempts have been made for the enhancement of PMMA characteristics. Addition of fillers is a practical method for this purpose. Many factors may contribute to fracture of denture base such as high frenal attachment, heavy occlusal loads, trauma, insufficient polymerization, residual monomers, 
or poor denture adaptation.

Therefore, many studies have been conducted on the properties of denture base materials, location and time of crack propagation, and reasons for fracture. ${ }^{(7-9)}$

Compressive strength refers to the strength and stiffness of a cylindrical sample that is vertically supported and is compassed in the same direction. To reduce the risk of fracture of the denture base, multiple factors such as preparation techniques, and physical and chemical properties of materials should be considered. ${ }^{(10,11)}$ Also, a compressive resistance test should be performed. (12) Because of the importance of the subject, the aim of this in vitro study was to evaluate and compare the compressive strength of three different types of heat-cure acrylic resins namely Acropars, Acrosun, and Meliodent.

\section{Materials and Methods}

In this in vitro experimental study, 60 acrylic samples were fabricated from Acropars, Acrosun, and Meliodent ( $\mathrm{n}=20$ from each) using molds. Cylindrical specimens were fabricated in 6 aluminum molds measuring $4 \mathrm{~mm} \times 10 \mathrm{~mm}$. After preparation of the molds, petroleum jelly was applied on the walls of the molds to prevent the attachment of wax to the molds in the waxing stage; then, melted modeling wax was poured into the cylindrical molds while using a dental catheter to prevent void and defect formation. Next, with the help of an expert technician, the process of flasking was done with type 2 plaster ${ }^{(13)}$ Flasks were placed under the pressure of a hydraulic press machine for 10 minutes; then, they were placed in cold water and after that, they were sintered. The flasks were placed in water at $70^{\circ} \mathrm{C}$ temperature for 8 hours. Then, they were placed in water at $100^{\circ} \mathrm{C}$ temperature for 1 hour. The water temperature was checked by a thermometer during the entire process. ${ }^{(14)}$ Finally, all specimens remained at room temperature for 24 hours to cool down. ${ }^{(15)}$ The flasks were opened carefully to remove the samples. A Sandblaster was used to remove the plaster attached to the samples. All samples were measured to be of the same size.

The study groups were as follows:

1. Group A: Acropars acrylic resin (Marlic Co.,
Tehran, Iran) $(\mathrm{n}=20)$

2. Group B: Acrosun acrylic resin (Betadent Co., Iran) $(\mathrm{n}=20)$

3. Group C: Meliodent acrylic resin (Bayer Co., New Burg, Germany) $(\mathrm{n}=20)$

All specimens were fabricated under the same conditions with the powder-liquid ratio of 3:1 according to the manufacturer's instructions. To measure the compressive strength, the samples were placed in a universal testing machine and load was applied at a crosshead speed of $1 \mathrm{~mm} /$ minute until the fracture of acrylic resin sample; the load at failure was recorded as compressive strength. ${ }^{(16)}$

\section{Statistical analysis:}

Data analysis was performed using SPSS version 22. ANOVA was used to compare the compressive strength of the three groups. The Tukey's test was applied for pairwise comparisons. The significance level was set at 0.05 .

\section{Results}

The compressive strength of the three experimental groups is shown in table 1 .

Table 1. Compressive strength of the three groups

\begin{tabular}{cccccc}
\hline Acrylic type & $\begin{array}{c}\text { Mean } \\
(\mathrm{MPa})\end{array}$ & $\begin{array}{c}\text { Standard } \\
\text { Deviation }\end{array}$ & Max. & Min. & P-value \\
\hline Acropars & 80.6 & 6.9 & 94.5 & 65 & \\
Acrosun & 85.6 & 6.9 & 101.33 & 72.08 & 0.047 \\
Meliodent & 71.9 & 5.3 & 80.25 & 62 & \\
\hline
\end{tabular}

The results indicated that Acrosun had the maximum and Meliodent had the minimum mean compressive strength. One-way ANOVA showed a significant difference in compressive strength of the three groups $(\mathrm{P}=0.047)$. Thus, pairwise comparisons were performed by the Tukey's test, which showed a significant difference in the compressive strength of Acropars and Acrosun $(\mathrm{P}=0.047)$, Acropars and Meliodent $(\mathrm{P}=0.00)$, and Acrosun and Meliodent $(\mathrm{P}=0.00)$ groups (Table 2). 
Table 2. Pairwise comparisons of the groups by the Tukey's test

\begin{tabular}{cccc}
\hline Group A & Group B & $\begin{array}{c}\text { Mean Difference } \\
\text { (A-B) }\end{array}$ & P value \\
\hline Acropars & Acrosun & -4.95 & 0.047 \\
Acropars & Meliodent & 8.73 & 0.000 \\
Acrosun & Meliodent & 13.69 & 0.000 \\
\hline
\end{tabular}

\section{Discussion:}

Fracture of denture base is a common problem. Therefore, various methods have been used to reduce the risk of fracture and provide proper masticatory function, optimal esthetics, and speech. Auto-polymerized acrylic resins have shown lower compressive strength in comparison with heat-cure acrylic resins, which is due to the higher amount of residual monomers in auto-polymerized acrylic resins. ${ }^{(17)}$ Assessment of the compressive and flexural strength of denture base materials is beneficial since the forces applied to dentures during mastication can be simulated as such. Previous studies did not agree on the mechanical and chemical properties of acrylic resins. Gharehchahi et al. ${ }^{(18)}$ evaluated the bond strength of two heat-cure acrylic resins namely glass-reinforced Meliodent and Acropars. In contrast to the results of the present study, they showed no significant difference between the two acrylic resins. However, Gungor et al. ${ }^{(19)}$ found different flexural and compressive strength values of denture base materials depending on their polymerization method. They reported that the flexural and compressive strengths of polymerized acrylic resins were higher when using short cycle polymerization, which included $90 \mathrm{~min}$ utes at $73^{\circ} \mathrm{C}$ and then 30 minutes at $100^{\circ} \mathrm{C}$ compared with long polymerization cycle ( 9 hours of polymerization). Their results are consistent with the results of the present study despite different methodologies.

In another study, Hashem et al. ${ }^{(17)}$ found that Eclipse acrylic resin had higher compressive and flexural strength values compared with Meliodent acrylic resin. This might be due to higher polymerization temperature or crystalline formulation of the former acrylic resin, resulting in fewer voids and gaps in it. Durkan and Oyar ${ }^{(13)}$ stated that the highest flexural and compressive strength values were related to Paladin acrylic resin, and the lowest values was recorded for Meliodent, which is consistent with our results. According to a study by Ellakwa et al, ${ }^{(3)} \mathrm{Al} 2 \mathrm{O} 3$ fillers, as components added to denture base materials, have the potential to increase the bond strength and heat dissipation, and also, improve the flexural strength and heat transfer properties of acrylic resin base. These properties increase patient satisfaction.

Begum et al. ${ }^{(20)}$ evaluated the impact strength and dimensional accuracy of heat-cure PMMA reinforced with $\mathrm{ZrO} 2$ nanoparticles, and reported that reinforcement of heat-cure PMMA with $\mathrm{ZrO} 2$ nanoparticles significantly increased the dimensional accuracy and decreased the impact strength. Recently, the advent of computer-aided design and computer-aided manufacturing (CAD/ CAM) technology enabled the fabrication of complete dentures from PMMA blocks. Accordingly, Al-Dwairi et al. ${ }^{(21)}$ compared the flexural strength, impact strength, and flexural modulus of CAD/CAM and heat-cure PMMA. Their results showed that since CAD/CAM PMMA specimens exhibited improved flexural strength, flexural modulus, and impact strength in comparison with the conventional heat-cure groups, $\mathrm{CAD} /$ CAM dentures are expected to be more durable. Khan et al. ${ }^{(22)}$ reported that the flexural strength of heat-cure PMMA denture base did not statistically improve after reinforcement with zinc powder in different concentrations. Moreover, Maheshwari and Parihar ${ }^{(23)}$ reported that heat-cure acrylic resin had higher compressive and flexural strength, and hardness in comparison with other types of acrylic resins, which was in line with our study.

In the present study, samples were fabricated in a size larger than the actual size of restorations in the oral cavity to enhance measurement of their compressive strength. In clinical conditions, the maximum thickness of acrylic resin in the palate area is $2.5 \mathrm{~mm}$, and increasing the thickness of specimens increases the likelihood of void formation or incomplete polymerization and can compromise the accuracy of the results. 
of this study, it could not completely simulate the intraoral conditions. Therefore, clinical studies are required to confirm the present results.

\section{Conclusion:}

Considering the limitations of this study, the following results were drawn: Acrosun had the highest compressive strength compared with Meliodent and Acropars. The lowest compressive strength was related to Meliodent. These results confirmed the optimal compressive strength of Iranian acrylic resin. Dental clinicians can use it considering its cost-effectiveness and easy availability.

Declaration of interest

The authors declare no competing interests.

\section{References:}

1.Gad MM, Fouda SM, Al-Harbi FA, Näpänkangas R, Raustia A. PMMA denture base material enhancement: a review of fiber, filler, and nanofiller addition. Int $\mathrm{J}$ Nanomedicine 2017;12:3801-12.

2.Ghaffari T, Hamedirad F, Ezzati B. In Vitro comparison of compressive and tensile strengths of acrylic resins reinforced by silver nanoparticles at $2 \%$ and $0.2 \%$ concentrations. $\mathrm{J}$ Dent Res Dent Clin Dent Prospects 2014 Dec;8(4):204-9.

3.Ellakwa AE, Morsy MA, El-Sheikh AM. Effect of aluminum oxide addition on the flexural strength and thermal diffusivity of heat-polymerized acrylic resin. J Prosthodont 2008 May; 17(6):439-44.

4.Jagger DC, Jagger RG, Allen SM, Harrison A. An investigation into the transverse and impact strength of "high strength" denture base acrylic resins. J Oral Rehabil 2002 Mar;29(3):263-7.

5.Hong G, Murata H, Li Y, Sadamori S, Hamada T. Influence of denture cleansers on the color stability of three types of denture base acrylic resin. J Prosthet Dent 2009 Mar;101(3):205-13.

6.Asli HN, Moradian S, Asli MN. Comparison of transverse strength of three different types of heat cured resin acrylics. Biosci Biotechnol Res Commun 2017;10(2):248-51.

7.Vallittu PK. Glass fiber reinforcement in repaired acrylic resin removable dentures: preliminary results of a clinical study. Quintessence Int 1997 Jan;28(1):39-44.

8.Beyli MS, von Fraunhofer JA. An analysis of causes of fracture of acrylic resin dentures. J Prosthet Dent 1981 Sep;46(3):238-41.

9.Farmer JB. Preventive prosthodontics: maxillary denture fracture. J Prosthet Dent 1983 Aug;50(2):172-5.

10. Gharechahi J, Asadzadeh N, Shahabian F, Gharechahi M. Flexural strength of acrylic resin denture bases processed by two different methods. J Dent Res Dent Clin Dent Prospects $2014 \mathrm{Sep} ; 8(3): 148-52$.

11. Hammed MG, Al-Fahdawi IH, Motlak M. Enhancement of the Tensile and the Compression Properties for HeatCured Acrylic Resin Denture Base Materials. Baghdad Sci J 2018;15(4):449-54
12. Ersu B, Yuzugullu B, Ruya Yazici A, Canay S. Surface roughness and bond strengths of glass-infiltrated aluminaceramics prepared using various surface treatments. J Dent 2009 Nov;37(11):848-56.

13. Durkan R, Oyar P. Comparison of mechanical and dynamic mechanical behaviors of different dental resins polymerized by different polymerization techniques. Niger J Clin Pract 2018 Sep;21(9):1144-9.

14. Heidari B, Firouz F, Izadi A, Ahmadvand S, Radan P. Flexural strength of cold and heat cure acrylic resins reinforced with different materials. J Dent (Tehran) 2015 May;12(5):316-23.

15. Abdulhamed AN, Mohammed AM. Evaluation of thermal conductivity of alumina reinforced heat cure acrylic resin and some other properties. J Bagh Coll Dent. 2010;22(3):1-6.

16. Nejatian T, Sefat F, Johnson T. Impact of packing and processing technique on mechanical properties of acrylic denture base materials. Materials 2015;8(5):2093-109.

17. Hashem M, Alsaleem SO, Assery MK, Abdeslam EB, Vellappally S, Anil S. A comparative study of the mechanical properties of the light-cure and conventional denture base resins. Oral Health Dent Manag 2014 Jun;13(2):311-5. 18. Gharehchahi J, Aghdaee NA, Kermani N. Evaluation of FRC reinforcing on flexural strength of acrylic resin denture bases. N Y State Dent J 2010 Nov;76(6):40-3.

19. Gungor H, Gundogdu M, Alkurt M, Yesil Duymus Z. Effect of polymerization cycles on flexural strengths and microhardness of different denture base materials. Dent Mater J 2017 Jan;36(2):168-73.

20. Begum SS, Ajay R, Devaki V, Divya K, Balu K, Kumar PA. Impact strength and dimensional accuracy of heat-cure denture base resin reinforced with $\mathrm{ZrO} 2$ nanoparticles: $\mathrm{An}$ in vitro study. J Pharm Bioallied Sci 2019 May;11(Suppl 2):S365-70.

21. Al-Dwairi ZN, Tahboub KY, Baba NZ, Goodacre CJ. A Comparison of the flexural and impact strengths and flexural modulus of $\mathrm{CAD} / \mathrm{CAM}$ and conventional heat-cured polymethyl methacrylate (PMMA). J Prosthodont 2020 Jun;29(4):341-9.

22. Khan H, Raza M, Khan TA. Comparison of flexural strength of Zinc nanoparticles reinforced resin with conventional heat cure acrylic resin. Pak Oral Dent J 2020; 40(1):51-4.

23. Maheshwari J, Parihar R. A Comparative evaluation of impact strength, compressive strength, tensile strength, hardness and dimensional accuracy of autopolymerized, postpolymerized microwave exposed autopolymerized and heat-cured denture base resins-An in vitro study. Saudi J Oral Dent Res. 2018;3(5): 164-70.

Cite this paper as: Neshati A, Kouchak Dezfouli N, Sadafi M, Omidi S. Compressive Strength of Three Types of Heat-Cure Acrylic Resins:Acropars, Acrosun, and Meliodent. J Res Dent Maxiilofac Sci. 2021;6(4):14-17. 